\title{
Thermal Comfort of the Kitchen in Pantry Cars on Indian Railways
}

\author{
Md Sarfaraz Alam*, Arunachalam Muthiah, Urmi Ravindra Salve \\ Department of Design, Indian Institute of Technology Guwahati, Guwahati 781039, Assam, India
}

Corresponding Author Email: sarfaraz8665@iitg.ac.in

https://doi.org/10.18280/i2m.180506

Received: 13 June 2019

Accepted: 9 August 2019

\section{Keywords:}

thermal sensation, neutral temperature, comfort range, predicted mean vote $(P M V)$, predicted percentage dissatisfied $(P P D)$

\begin{abstract}
This paper mainly investigates the thermal comfort of the kitchen in pantry cars on Indian railways in two seasons (summer and winter) and two climatic zones (humid and subtropical climate zone and tropical wet and dry climate zone). A questionnaire survey on subjective feelings of thermal comfort was conducted among 69 chefs working in 14 kitchens of pantry cars on Indian railways. Their physical parameters of thermal comfort were also measured. Based on the survey results and measured data, the authors analyzed the comfort perception and thermal responses of the chefs in the kitchens, with the aid of indices like predicted mean vote (PMV) and predicted percentage dissatisfied (PPD). The results show that outdoor environmental parameters have an effect on indoor environmental parameters during the cooking; the maximum range of thermal comfort parameters was found at lunch and snack preparations, while the minimum was observed at breakfast; the PMV/PPD index method does not apply directly to the evaluation of thermal comfort in the kitchen in pantry cars on railways; the neutral temperature of chefs in summer and winter was $23^{\circ} \mathrm{C}$ and $21.62^{\circ} \mathrm{C}$, respectively. These findings help to improve the indoor working environment of chefs on Indian railways.
\end{abstract}

\section{INTRODUCTION}

Indian Railways is one of the second biggest rail networks in the world in the 21 st century. It plays a vital role in transportation facilities, which carries more than twenty million passengers and more than two million tons of freight regularly [1]. Moreover, 12,000 passenger trains like; mail, express, and superfast-express trains run throughout the country [2]. Catering system is one of the main characteristics of Indian railways, which provides food to railway passengers through its present approximately 338 pairs of railway pantry car coaches and 11,237 catering-stalls [3]. Pantry car, play a significant role in the catering system, it serves the food, onboard passengers, which is an integral part of every medium and long route train $[3,4]$. In a pantry car coach, there are 3-5 chefs, while 40-50 meal servers, and 2 railway pantry car employees $[5,6]$. There are two types of pantry car coaches' model running at present, such as; air-conditioned and non-airconditioned. Air-conditioned pantry car coaches have a better aesthetic design and equipped with better passenger comfort but as per the previous research indicated that at the cooking time there is no significant difference in thermal environment between both these two types of pantry car coaches [6]. Both these pantry cars use common equipment for cooking such as; ovens, heater, kettle, soup warmer, deep fryers, etc. While preparation of the meal these types of instrument leads to humidity, fumes and heat generation. Because of this, the indoor environment of a pantry car kitchen becomes severely hot and humid [7]. The existing hot and humid conditions cause excessive sweating and make chefs work difficult in a pantry car, which is not conducive to human work. This uncomfortable situation of work adversely affects the physical and mental health of the chefs. No researcher has concentrated on an appraisal of the situation of chef's thermal comfort in pantry car kitchen. While few researchers have studied the thermal environment in commercial kitchens.

Ravindra et al. [8] organized the thermal comfort research in a household kitchen in Punjab, in this paper identify the thermal sensation range during winter season slightly cool to neutral and neutral to slightly warm during the summer season. Similarly, research of Rahmillah et at. [9] indicated the PMV and PDD index results found the 'hot' thermal sensation value and most of the subjective responses voted to preferred morning cooking time in the kitchen. Kajtar et al. [10] observed the environmental parameters demonstrated a higher percentage of dissatisfaction than a complaint of occupancy in the kitchen environment. Whereas, the "non-uniform" thermal environmental situation in a home kitchen, when the outer air temperature is low the temperature inside the kitchen changes drastically, especially in the outer window region [11]. Similarly, the result of Livchak et al. [12] shows that when the temperature inside the kitchen becomes $5.5^{\circ} \mathrm{C}$ more than comfort temperature, the productivity would have reduced by $30 \%$. The research of Simone et al. [13] determined that PMVPPD method is not directly applicable for commercial kitchen environment due to high globe temperature, air temperature, and high level of activity.

Above mentioned research shows that different studies concerned to thermal comfort are available for commercial kitchen workers, and factors affecting the human thermal comfort has considered. While literature related to these issues has not been found on the Indian railway's pantry car kitchen. However, railway pantry cars are similar to commercial kitchens, but there is some difference in this such as; workflow, job demand, indoor architecture, and moving nature of the railway pantry car. Therefore, this research article efforts to appraisal the thermal comfort in a railway pantry car kitchen in Indian by utilizing objective measurement and subjective 
assessment.

It has the following objectives:

1. Compare indoor and outdoor environmental factors based on seasonal and climatic zone variations during the different cooking times (breakfast, lunch, snack, and dinner);

2. To evaluate whether the PMV model is applicable or not for predicting the thermal comfort of chefs in Indian railway pantry car kitchens, and identify the neutral (comfort) temperature for them.

\section{METHOD}

\subsection{Location, duration and subject description}

\subsubsection{Location}

This research was carried out in two different types of climatic zones in India under the climatic classification of the Koppen system shown in Figure 1. The indoor and outdoor thermal environment factors of the Indian Railway Pantry Car (IRPC), was measured in humid and sub-tropical, and tropical wet and dry climatic zone at different railway stations. In a humid and subtropical climate zone, the data has been taken from both up and down trains from Guwahati to Delhi railway station. While trains between Kolkata to Hyderabad has been considered for tropical wet and dry climate zone. Most of the medium and long, distance trains with the pantry cars travel through these two major climatic zones. In this study, other climate zones such as; tropical wet and arid have not been monitored because, in this climate area, only a few trains run with a pantry car, and most of the trains run in the night. However, some trains run during the day time but they do not travel throughout this climate zone for the entire day.

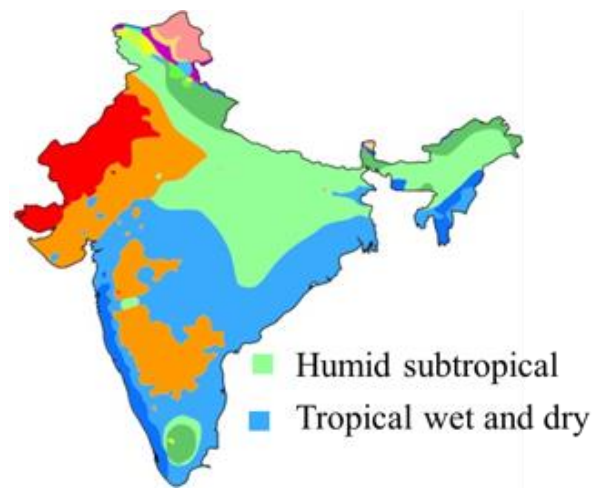

Figure 1. Climatic zones in India, based on the Koppen classification system

\subsubsection{Duration}

In the current study, two seasons have been selected like winter and summer. Therefore, the period of study was for the summer season in August and similarly, it was in December for the winter season. Both seasons data was taken in 2018 only. Because of safety and security intentions, the duration of this study was fixed for only sixteen days for each season. In both climate zones and seasons, during the preparation of the meal inside the pantry car, all indoor and outdoor physical measurement data were recorded: breakfast "7:00 am", lunch "11:30 am", snack "4:00 pm" and dinner "6:30 pm". During night time, chefs do not cook food inside the pantry car. Usually, the chefs close the cooking process from 8:00 pm to 9:30 pm. Therefore, this study has been done only during the whole cooking period of the entire day. These measurements were observed as much as possible without troubling the respondent's activities.

\subsubsection{Subject description}

A total number of 338 trains in India run with a pantry car which has been reported in the railway board report. In which, there are 3 to 5 cooking workers (chefs) in a train. The determine sample size was 64 on the total chef's population (1352) and confidence interval of 12. In this study, the survey was conducted on a total number of 14 IRPCs. In which 69 chefs were taken. During summer season, 6 IRPCs were considered, in which total 29 chefs were included. There were 19 chefs from 4 IRPCs in humid and subtropical climate zone, and 10 chefs from 2 IRPCs in a tropical wet and dry climate zone. Similarly, in the winter season, a total number of 8 IRPCs were surveyed between 40 chefs. There were 30 chefs from 6 IRPCs in humid and subtropical climate zone, and rest of the 10 chefs from 2 IRPCs in a tropical wet and dry climate zone. All of these chefs were from different states. The general education level of chefs was found to be very low, very few among them were even matriculate.

\subsection{Data collection}

2.2.1 Physical measurement data: Indoor and outdoor environmental parameters

The thermal comfort physical parameters recorded were "air temperature", "mean radiant temperature", "relative-humidity", and "air-velocity". The study comprises indoor and outdoor environmental parameters that were measured with the support of (a) handheld anemometer: Kestrel weather meter 4500, (b) 6 -inch black-globe thermometer. The accuracy and range of the instrument have been depicted in Table 1. Data of environmental parameters were measured according to ASHRAE 55 Standard [14] and Simone and Olson [15], In which, "air temperature- $\mathrm{t}_{\mathrm{a}}$ ", "globe temperature- $\mathrm{t}_{\mathrm{g}}$ ", "relative

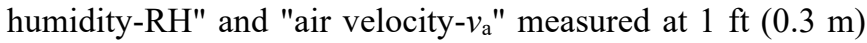
near the workstation and 43 in. $(1.1 \mathrm{~m})$ above the workstation floor in the IRPCs kitchen (where the time of cooking [breakfast, lunch, snacks, and dinner] chef's operating hours were at peak throughout the day). All these physical measurements were observed during the meal preparation time as discussed above. All physical parameters were recorded indoor environment of the pantry car for 10-15 minutes and the outdoor environment of the pantry car for 5-10 minutes with the $5 \mathrm{~s}$ to $10 \mathrm{~s}$ interval. The train generally stops at the designated railway station for a very short time, due to this the timing of outdoor parameters measurement has been considered less.

The globe temperature was measured with the help of a "(6 in.)-black globe thermometer" in the center position of the meal preparing zone as discussed above, which estimates the "mean radiant temperature". As per the Mishra and Ramgopal [16], mean radiant temperature " $\mathrm{t}_{\mathrm{mrr}}$ " was approximated with the combination of "air temperature- $t_{a}$ ", "globe temperature$\mathrm{t}_{\mathrm{g}}$ ", and "air velocity- $v_{\mathrm{a}}$ " applying Eq. (1).

$$
t_{m r t}=\left[\left(t_{g}+273\right)^{4}+\frac{1.1 \times 10^{8} v_{a}{ }^{0.6}}{\varepsilon D^{0.4}} \times\left(t_{g}-t_{a}\right)\right]^{1 / 4}-273
$$

where, emissivity of the globe surface (has assumed as 0.95) is ' $\varepsilon$ ' and globe diameter is ' $\mathrm{D}$ '. 
Table 1. Details of instruments used during the field study

\begin{tabular}{|c|c|c|c|}
\hline $\begin{array}{c}\text { Instrument } \\
\text { and type }\end{array}$ & $\begin{array}{c}\text { Parameter } \\
\text { measured }\end{array}$ & Range & Accuracy \\
\hline \multirow{3}{*}{$\begin{array}{l}\text { Kestrel weather } \\
\text { meter } 4500\end{array}$} & $\begin{array}{l}\text { (i) Indoor and } \\
\text { outdoor air } \\
\text { temperature, } T_{a}\end{array}$ & $\begin{array}{c}-29.0^{\circ} \mathrm{C} \text { to } \\
+70.0^{\circ} \mathrm{C}\end{array}$ & $\begin{array}{l}-5^{\circ} \text { to } \\
+95^{\circ} \mathrm{C}\end{array}$ \\
\hline & $\begin{array}{l}\text { (ii) Indoor and } \\
\text { outdoor relative } \\
\text { humidity, RH }\end{array}$ & $\begin{array}{c}5 \% \text { to } \\
95 \%\end{array}$ & $\pm 3 \%$ \\
\hline & $\begin{array}{l}\text { (iii) Indoor and } \\
\text { outdoor air } \\
\text { velocity, } V_{a}\end{array}$ & $\begin{array}{l}0.4 \mathrm{~m} / \mathrm{s} \text { to } \\
60 \mathrm{~m} / \mathrm{s}\end{array}$ & $\pm 0.1 \mathrm{~m} / \mathrm{s}$ \\
\hline $\begin{array}{l}\text { 6-inch black- } \\
\text { globe } \\
\text { thermometer }\end{array}$ & $\begin{array}{l}\text { (i) Indoor and } \\
\text { outdoor globe } \\
\text { temperature, } T_{g}\end{array}$ & $\begin{array}{l}-5^{\circ} \text { to } \\
+95^{\circ} \mathrm{C}\end{array}$ & \\
\hline
\end{tabular}

2.2.2 Assessing clothing insulations and metabolic activity level

In this research for estimation of the "clothing insulation" and "metabolic activity level" using the standard checklist which is provided by ASHRAE 55 Standard [14] and ISO 7730 Standard [17]. Only male chefs work inside the IRPC. A pantry car chef commonly attired of Indian style outfit: which is a combination of "short-sleeved shirts or long-sleeved shirts", "short-sleeved dress shirts or long-sleeved dress shirts", "t-shirts", "men's briefs", "trousers/straight trousers (thin)/straight trousers (thick)" and shoes/slipper etc. We have taken 'Clo' value of all these items under, ASHRAE standard as exhibited in Table 2. The average metabolic activity level of the pantry car chefs was examined during the cooking time to be nearly 2.0 met $\left(116 \mathrm{~W} / \mathrm{m}^{2}\right)$ [18]. And it shows that the chefs were mostly "standing" and "medium" activity, according to ASHRAE 55 Standard [14] and ISO 7730 Standard [17].

Table 2. Insulating value of clothing elements

\begin{tabular}{ccc}
\hline Man & & Clo \\
\hline Under wear & singlets & 0.06 \\
& T-shirt & 0.09 \\
& briefs & 0.05 \\
& long, upper & 0.35 \\
Shirt & long, lower & 0.35 \\
& light, short sleeve & 0.14 \\
& light, long sleeve & 0.22 \\
& heavy, short sleeve & 0.25 \\
& heavy, long sleeve & 0.29 \\
Vest & $+5 \%$ for tie or turtle-neck & \\
& light & 0.15 \\
Trousers & heavy & 0.29 \\
& light & 0.26 \\
Pullover & heavy & 0.32 \\
& light & 0.20 \\
Jacket & heavy & 0.37 \\
& light & 0.22 \\
Socks & heavy & 0.49 \\
& ankle length & 0.04 \\
Footwear & knee length & 0.10 \\
& sandals & 0.02 \\
& shoes & $0.04 \mathrm{a}$ \\
& boots & 0.08 \\
\hline
\end{tabular}

\subsubsection{PMV-PPD index calculation}

The PMV "Predicted mean vote" and PPD "Predicted percentage dissatisfied" index method was established by Fanger's (1970) applying "heat-balance equations" and empirical research about "skin temperature" to determine comfort level. The measured environmental variables including "air temperature", "mean radiant temperature", "relative humidity" and "air velocity" along with the predicted "metabolic rate" and "clothing insulation" was used to compute the PMV-PPD index using a CBE "Center for the Built Environment" thermal comfort software to determine thermal comfort according to ASHRAE 55 Standard [19].

\subsubsection{Subjective assessments}

In the arrangement to appraise the thermal comfort of the indoor environment condition in IRPCs kitchen chef's activities, "subjective assessment" plays a vital role. A demographic data of the subject includes the parameters like age, weight, height, job experience; these were noted first in the checklist. After that, to identify the nature of subjective responses of the pantry car chef's standard checklist was used based on the ASHRAE 55 Standard [20], ISO 14505-3 Standard [21], and ISO 10551 Standard [22] as shown in Table 3. In which ASHRAE seven-point rating scale: -3 "cold" to +3 "hot" was applied to estimate the "thermal sensation vote TSV". Similarly, same rating Bedford scale from -3 "much too cool" to +3 "much too warm" were used to getting the thermal comfort votes (TCV) of the IRPCs kitchen chefs. The occupant's thermal preference response observed with the help of McIntyre index "3-point sensation scale" in which the response from -1 "cooler", 0 "no change" and +1 "warmer" as depicted in Table 3. Responses from acceptable (0) and not acceptable (1) has been taken for a rate of the overall thermal acceptability of the respondents inside the pantry car.

Table 3. Thermal comfort survey checklist of preferences and sensation for indoor parameters

\begin{tabular}{|c|c|c|c|c|}
\hline \multicolumn{5}{|c|}{ Description of scale } \\
\hline Scale & TSV & TCV & $\begin{array}{c}\text { Thermal } \\
\text { preference }\end{array}$ & $\begin{array}{c}\text { Thermal } \\
\text { acceptability }\end{array}$ \\
\hline+3 & Hot & $\begin{array}{l}\text { Much too } \\
\text { warm }\end{array}$ & & \\
\hline+2 & Warm & $\begin{array}{c}\text { Too } \\
\text { warm }\end{array}$ & & \\
\hline+1 & $\begin{array}{c}\text { Slightly } \\
\text { warm }\end{array}$ & $\begin{array}{c}\text { Ok } \\
\text { (Warm) }\end{array}$ & Warme & Not acceptable \\
\hline 0 & Neutral & $\begin{array}{l}\text { Ok (just } \\
\text { right) }\end{array}$ & No change & Acceptable \\
\hline-1 & $\begin{array}{c}\text { Slightly } \\
\text { cool }\end{array}$ & Ok (cool) & Cooler & \\
\hline-2 & Cool & Too Cool & & \\
\hline-3 & Cold & $\begin{array}{l}\text { Much too } \\
\text { cool }\end{array}$ & & \\
\hline
\end{tabular}

\subsection{Data analysis}

Present research comparison between the indoor and outdoor parameters of thermal comfort we used descriptive analysis in which the data presented as a maximum, minimum, and mean (SD). This comparative analysis had been investigated using a scatter plot between climate zones and season changes during food preparation inside the pantry car. The data was not normally distributed; therefore, graphical techniques were used to compare rather than statistical methods. Also, the difference between indoor and outdoor environmental parameters was high in the descriptive analysis itself. Therefore, performing statistical analysis (like T-test) was found to be unnecessary. For this MS Excel 2016 software has been incorporated. CBE thermal comfort software was used for the estimation of the PMV and PDD index model for 
each cooking period (breakfast, lunch, snacks, and dinner) inside the pantry car and It has also been tried to know whether this tool can be applicable for pantry car kitchen or not.

For assessment of subjective responses, "TCV", "TSV", 'thermal acceptability" and "thermal preference" votes have been used to determine the chef's perception in the present thermal environment. And the distribution of chef votes about thermal responses for each climate zone and season is reported with the help of a histogram of percentage data. While demographic detail like; age, height, weight and job experience data of pantry car chefs being reported as a range, percentage, mean (SD). To determine the "neutral temperature and comfort temperature range" of chefs inside the pantry car during the "summer and winter" season linear regression analyses were carried out using "Microsoft Office Excel 2016". After that, neutral (comfort) temperatures have been compared with ASHRAE standard and some other thermal comfort research conducted in hot and humid regions for validation of this study.

\section{RESULTS AND DISCUSSION}

\subsection{Indoor and outdoor environments}

Thermal comfort study basically consists of four important environmental factors such as; "air temperature", "radiant temperature (assessing through globe temperature)", "humidity" and "air velocity", which was measured in this research. The details of measured "indoor and outdoor" environmental variables observed during the seasonal and climatic variation are depicted in Table 4.

Table 4. Indoor and outdoor environmental factors based on the seasonal variation and climate zone

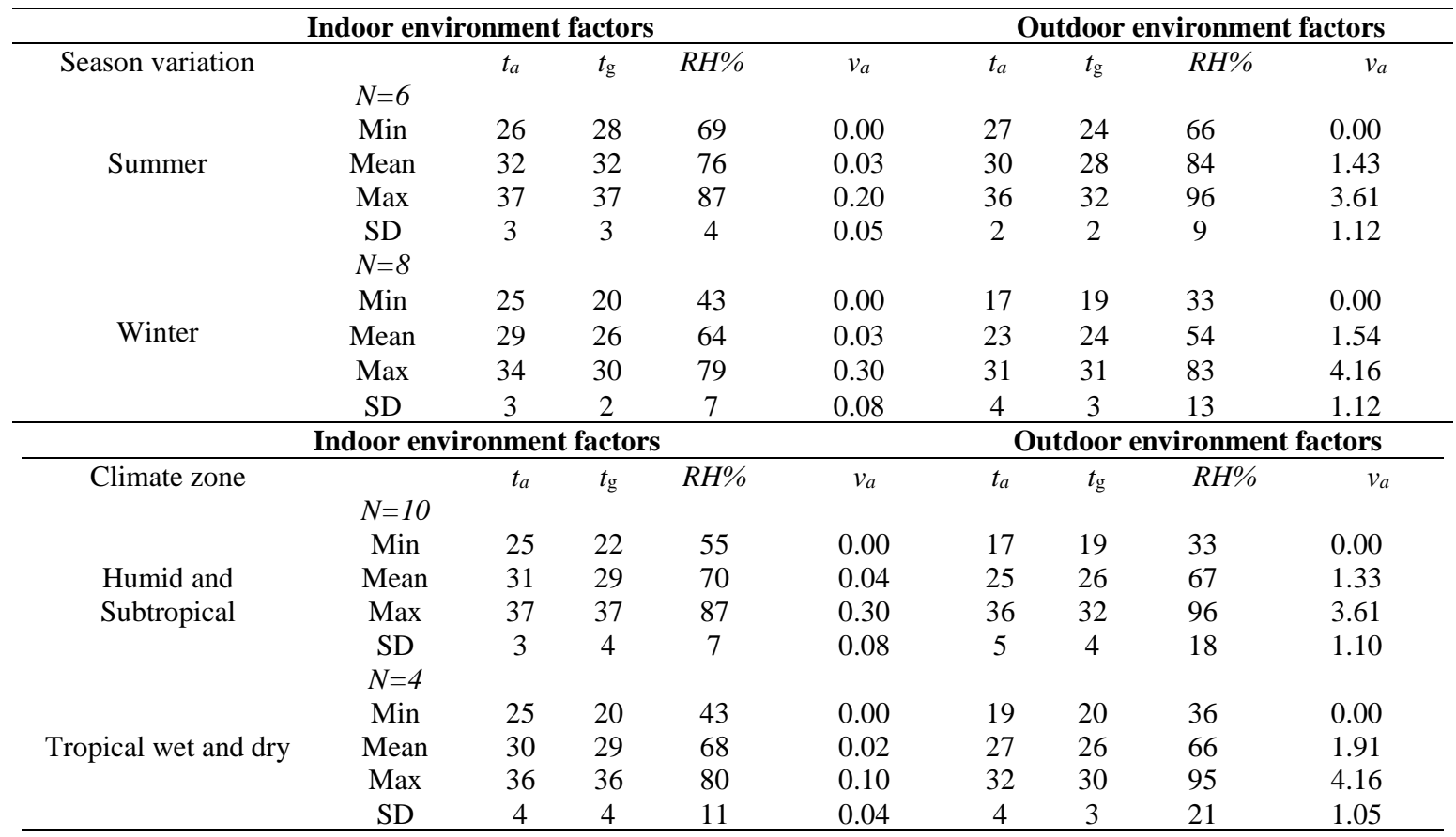

\subsubsection{Air temperature}

Air temperature is the most influential environmental factor for "thermal comfort", as shown in earlier studies. Which we have also taken in this study. Figure 2 (a) shows air temperature variation in the summer and winter season, which was taken in the indoor and outdoor sides of the pantry car kitchen. Generally, indoor and outdoor temperatures were measured four times a day during the cooking (breakfast, lunch, snacks, and dinner). According to a graphical representation, averages of indoor air temperature was found more in both seasons than the outdoor air temperature. During the summer season, maximum indoor air temperature was found to be $37^{\circ} \mathrm{C}$ snacks and $36^{\circ} \mathrm{C}$ lunch time. While the minimum indoor temperature was found at $26^{\circ} \mathrm{C}$ breakfast time. However, the average value of indoor air temperature in the entire summer season was $32^{\circ} \mathrm{C}$ during the all cooking period. And we can see that maximum and minimum values of outdoor air temperature are $36^{\circ} \mathrm{C}$ and $27^{\circ} \mathrm{C}$ respectively. In the winter season, it can be seen in the graph that the maximum value of indoor air temperature is up to $34^{\circ} \mathrm{C}$ lunch and snack time respectively. Whereas, the minimum indoor air temperature was $25^{\circ} \mathrm{C}$ breakfast and dinner time. However, during the cooking period of all time, the average value of the indoor air temperature was $29^{\circ} \mathrm{C}$ during the entire winter season. While throughout the winter season, the average value of outdoor air temperature was $23^{\circ} \mathrm{C}$.

Figure 2 (b) indicates indoor and outdoor air temperature variation in humid and sub-tropical and tropical wet and dry regions. It can be seen here also in the graph the indoor air temperature was higher than the outdoor air temperature in both climatic zones. In a humid and sub-tropical region, maximum indoor air temperature $37^{\circ} \mathrm{C}$ was found at the time of snack preparation in pantry car. However, the average value of indoor and outdoor air temperatures was $32^{\circ} \mathrm{C}$ and $25^{\circ} \mathrm{C}$ respectively throughout the entire period. Similarly, in a tropical wet and dry region maximum indoor air temperature $36^{\circ} \mathrm{C}$ was found at the time of lunch and snack preparation. While the entire cooking period, indoor and outdoor air temperature was found at $30^{\circ} \mathrm{C}$ and $27^{\circ} \mathrm{C}$, respectively.

As the above results indicate, there is a significant effect of outdoor air temperature inside the pantry car kitchen. Because indoor air temperature has always been found high throughout the whole study period. However, the value of indoor air temperature also does not comply with ASHRAE 55 Standard 
[19] both in the seasonal variation and climatic zones. Indoor air temperature has been found to be more at lunch and snack time in both summer and winter season and climatic zone (humid and sub-tropical and tropical wet and dry).

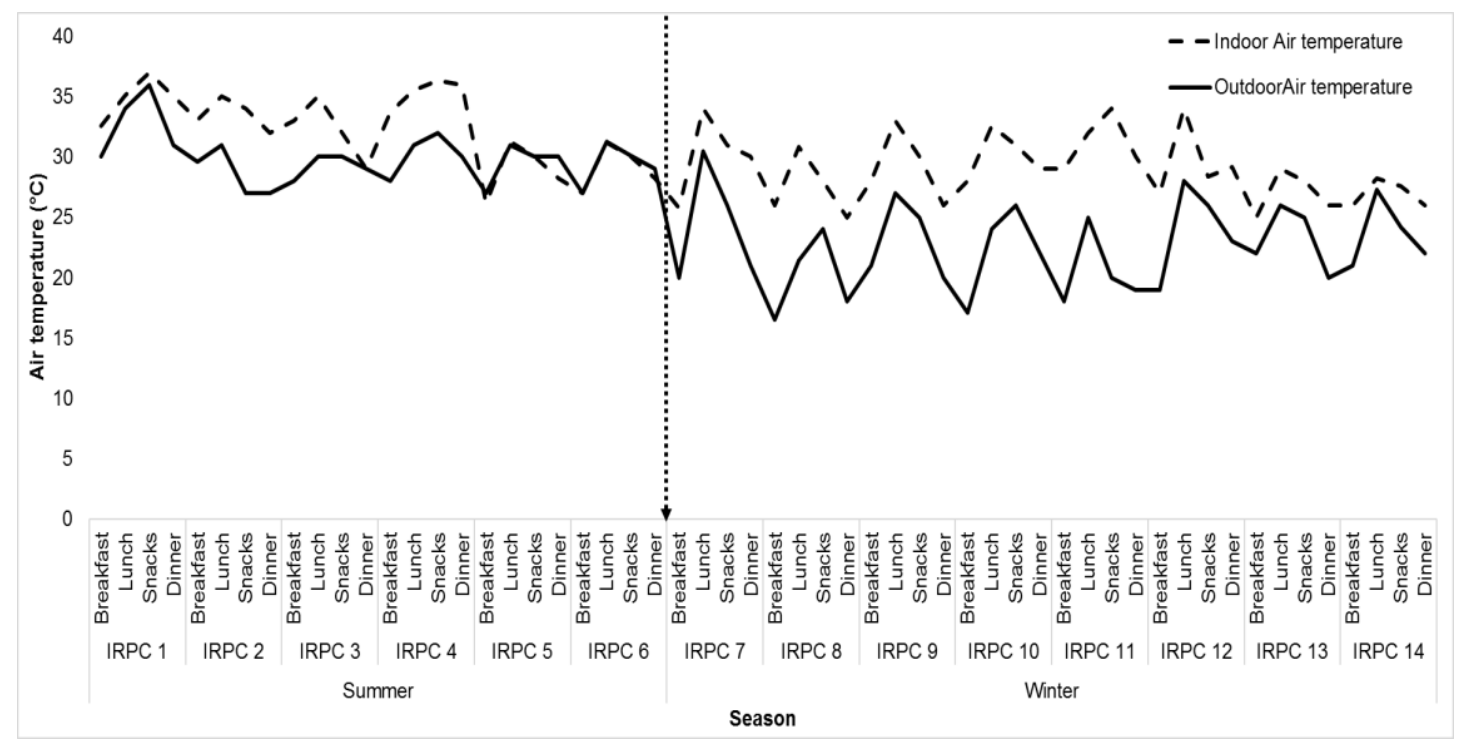

(a) Season

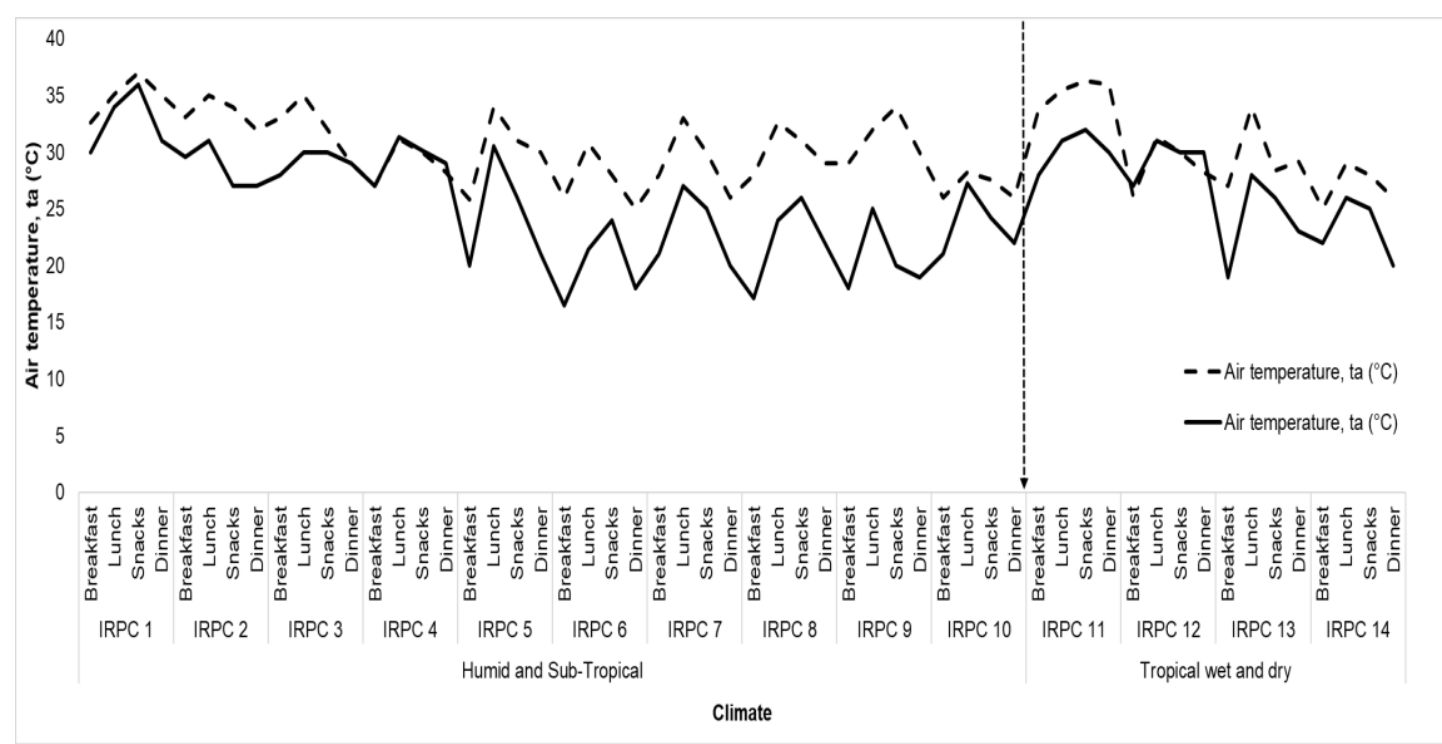

(b) Climate

Figure 2. Indoor and outdoor air temperature variation graph based on (a) season, and (b) climatic zone

\subsubsection{Globe temperature}

Figure 3 (a) shows the full measurements of globe temperature variation in both indoor and outdoor environmental conditions during summer and winter season. In the summer season, it can be seen that the maximum and minimum indoor global temperatures are $37^{\circ} \mathrm{C}$ snacks and $28^{\circ} \mathrm{C}$ breakfast at the time of cooking. Together, the average value of indoor globe temperature of the entire summer season was $32^{\circ} \mathrm{C}$. However, the average value of outdoor globe temperature was only $28^{\circ} \mathrm{C}$. In the entire summer season, the value of the indoor globe temperature was higher than the outdoor globe temperature. While during the winter season, the maximum and minimum indoor globe temperatures were found at $30^{\circ} \mathrm{C}$ lunch and $20^{\circ} \mathrm{C}$ breakfast time respectively. And in the entire winter season, the average indoor and outdoor global temperature was found at $26^{\circ} \mathrm{C}$ and $24^{\circ} \mathrm{C}$ respectively. In the winter season, the variation of the globe temperature varies less and more in both indoor and outdoor conditions. However, during the winter season also the indoor globe temperature did not obey the ASHRAE standards at some time of cooking.

Figure 3 (b) demonstrate the climate variation of globe temperature both indoor and outdoor environment. In a humid and subtropical climate region also the indoor globe temperature was maximum $37^{\circ} \mathrm{C}$ at snack time and its average value was found to be around $29^{\circ} \mathrm{C}$. Whereas, the average value of the outdoor globe temperature was $26^{\circ} \mathrm{C}$. Similarly, in a tropical wet and dry region, it can see that maximum indoor globe temperature was found on the same day $36^{\circ} \mathrm{C}$ and $35^{\circ} \mathrm{C}$ at the time of snacks and dinner respectively and the average value of this climate zone was $29^{\circ} \mathrm{C}$. Although, the average value of the outdoor globe temperature was $26^{\circ} \mathrm{C}$ throughout the tropical wet and dry region. The graphical result shows that the value of indoor globe temperature is almost the same during cooking in both climatic zones. While the outdoor globe temperature also did not get many variations. Even in this climate zone, the value of the indoor globe temperature does not follow the ASHRAE standard. 


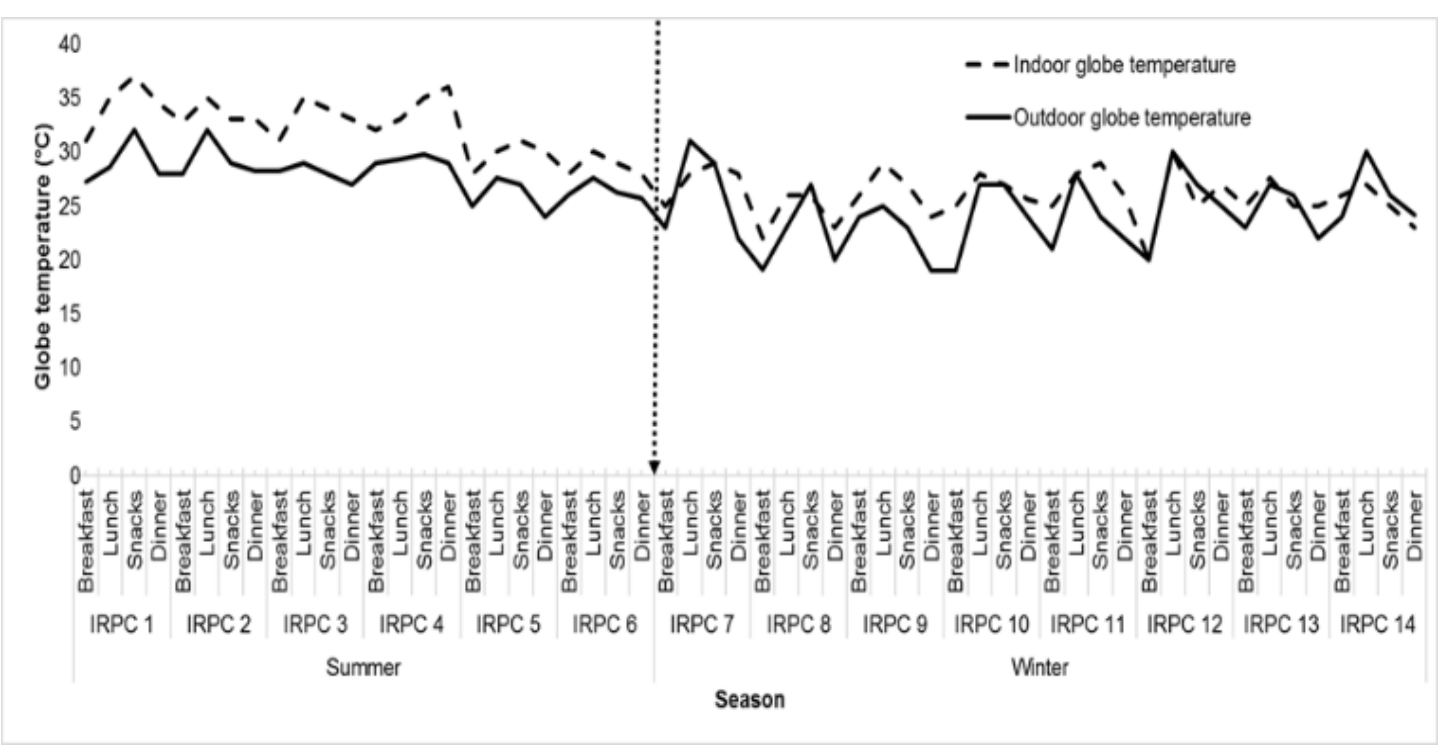

(a) Season

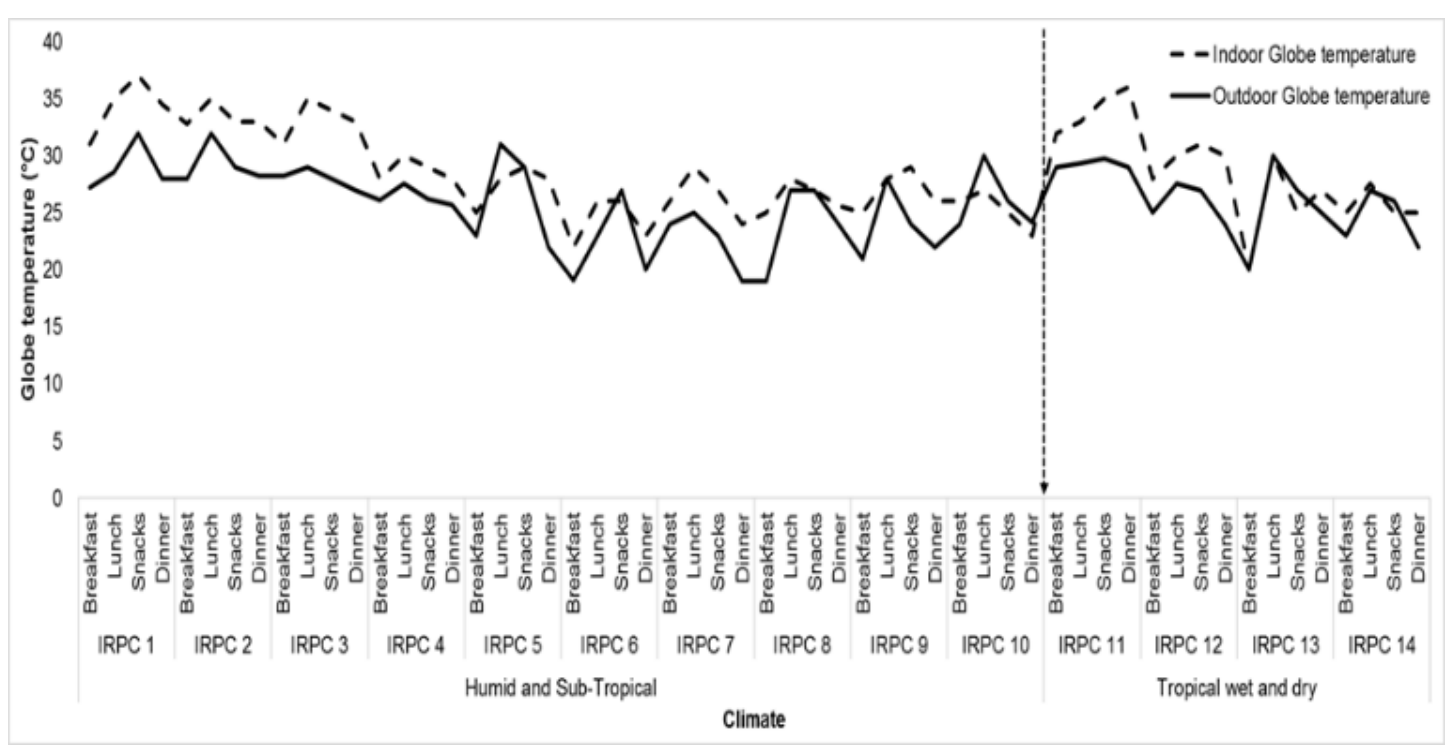

(b) Climate

Figure 3. Indoor and outdoor globe temperature variation graph based on (a) season, and (b) climatic zone

\subsubsection{Relative humidity}

Relative humidity ( $\mathrm{RH})$ is the vital factor representing the comfort level in the hot and humid environment and its high percentage may slow down the work process and cause discomfort. Figure 4 (a) shows the variation of relative humidity percentage $\mathrm{RH}(\%)$ in both indoor and outdoor environments during the summer and winter season. In the summer season, $87 \%$ and $69 \%$ of indoor RH were found the maximum and minimum respectively at the time of lunch and breakfast on a similar day. While the $76 \%$ average value of indoor RH measured throughout the summer season during the all cooking time. And the average value of the outdoor $\mathrm{RH}$ was 84\%. Approximately, the outdoor RH (\%) was estimated higher according to indoor in the entire summer season. Similarly in the winter season, the indoor and outdoor RH was recorded between $43 \%$ to $79 \%$ and $33 \%$ to $83 \%$, respectively. While the average rate of $\mathrm{RH} \%$ of both indoor and outdoor was $64 \%$ and $54 \%$. In the winter season, while preparing breakfast and lunch, humidity was found more inside the pantry car. Indoor and outdoor RH was found to be low in winter season as compared to the summer season. As per the ASHRAE 55 Standard [23], comfortable range of RH between
$30 \%$ to $60 \%$, optimum range of $\mathrm{RH}$ between $40 \%$ to $60 \%$ and considered ideal RH for $50 \%$.

Figure 4 (b) also shows the variation of RH (\%) on the based climatic zone both indoor and outdoor conditions. In the humid and sub-tropical climatic zone, the maximum indoor $\mathrm{RH}$ was at $87 \%$ lunch preparation time, while the different day minimum indoor $\mathrm{RH}$ was also found $55 \%$ at the lunch preparation time. However, rest of the other cooking time, the value of indoor RH value was found out of the recommended range. In this climate zone, the average rate of indoor and outdoor RH\% was $70 \%$ and $67 \%$ throughout the entire measurement respectively. Correspondingly in a tropical wet and dry region, the value of Indoor RH value was maximum and minimum at the time of breakfast $80 \%$ and lunch $43 \%$ respectively with $68 \%$ average value. Whereas outdoor RH in this climate zone was observed during all periods with an average rate of $66 \%$. As mentioned in previous studies, for the outdoor environment condition, when the temperature of the air increases, the relative humidity decreases [24]. In both the climate zone, indoor RH\% was found to be higher than the recommended range mostly while cooking. While the rate of outdoor RH fluctuated during this period. 


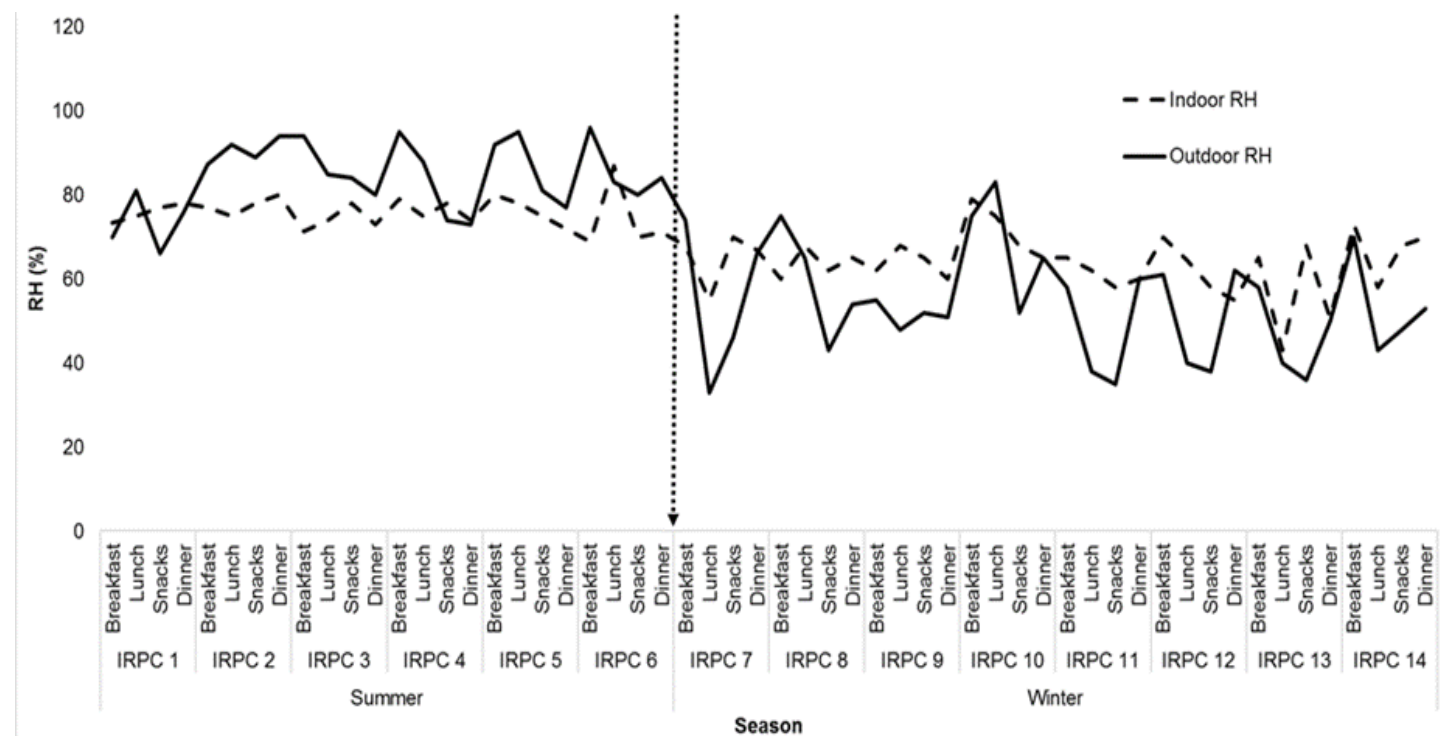

(a) Season

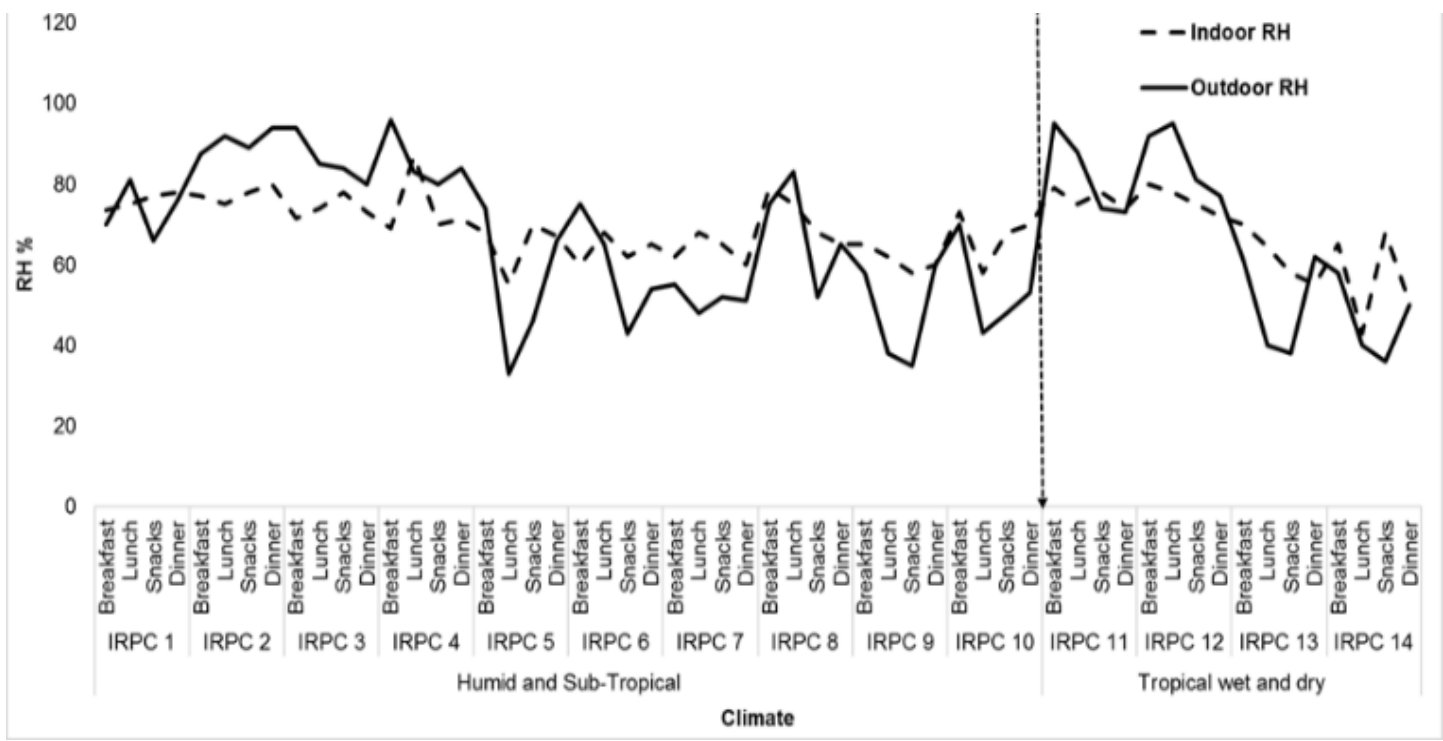

(b) Climate

Figure 4. Indoor and outdoor relative humidity variation graph based on (a) season, and (b) climatic zone

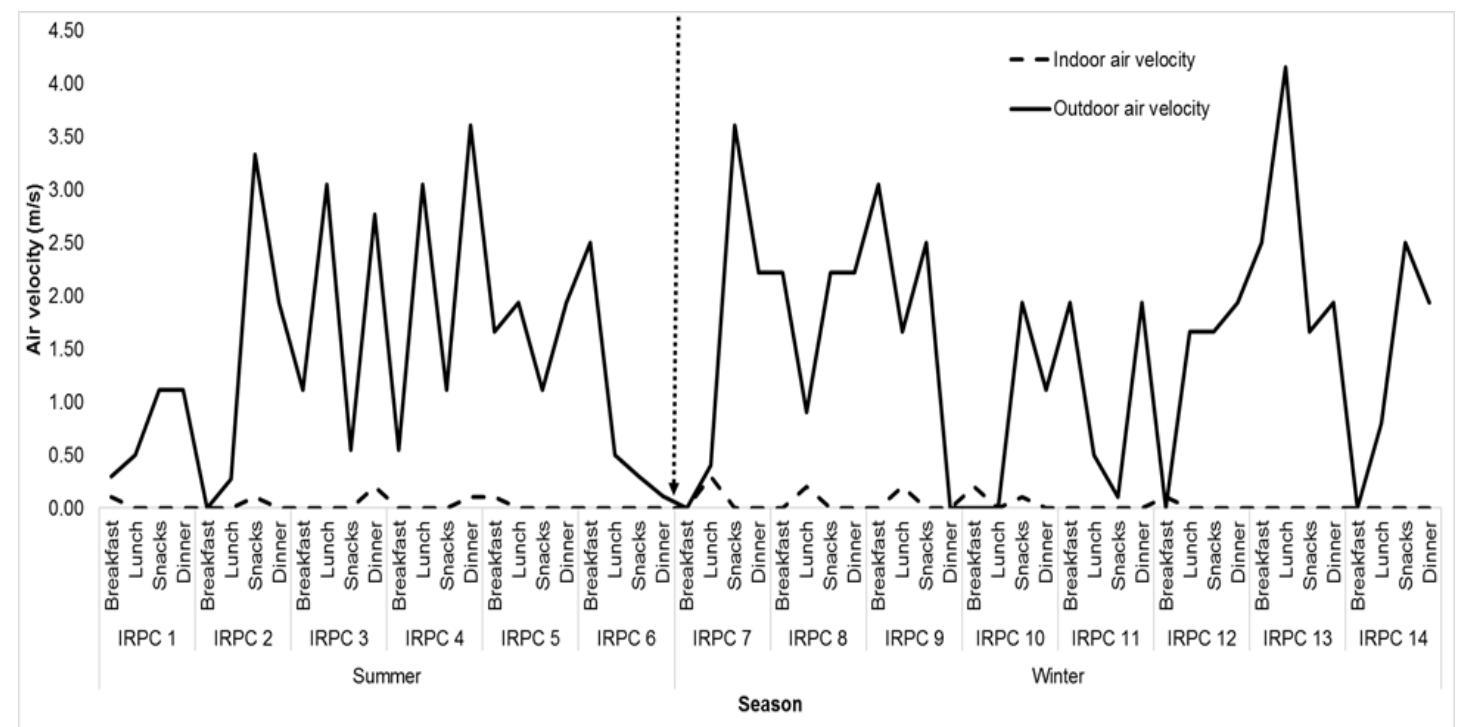

(a) Season 


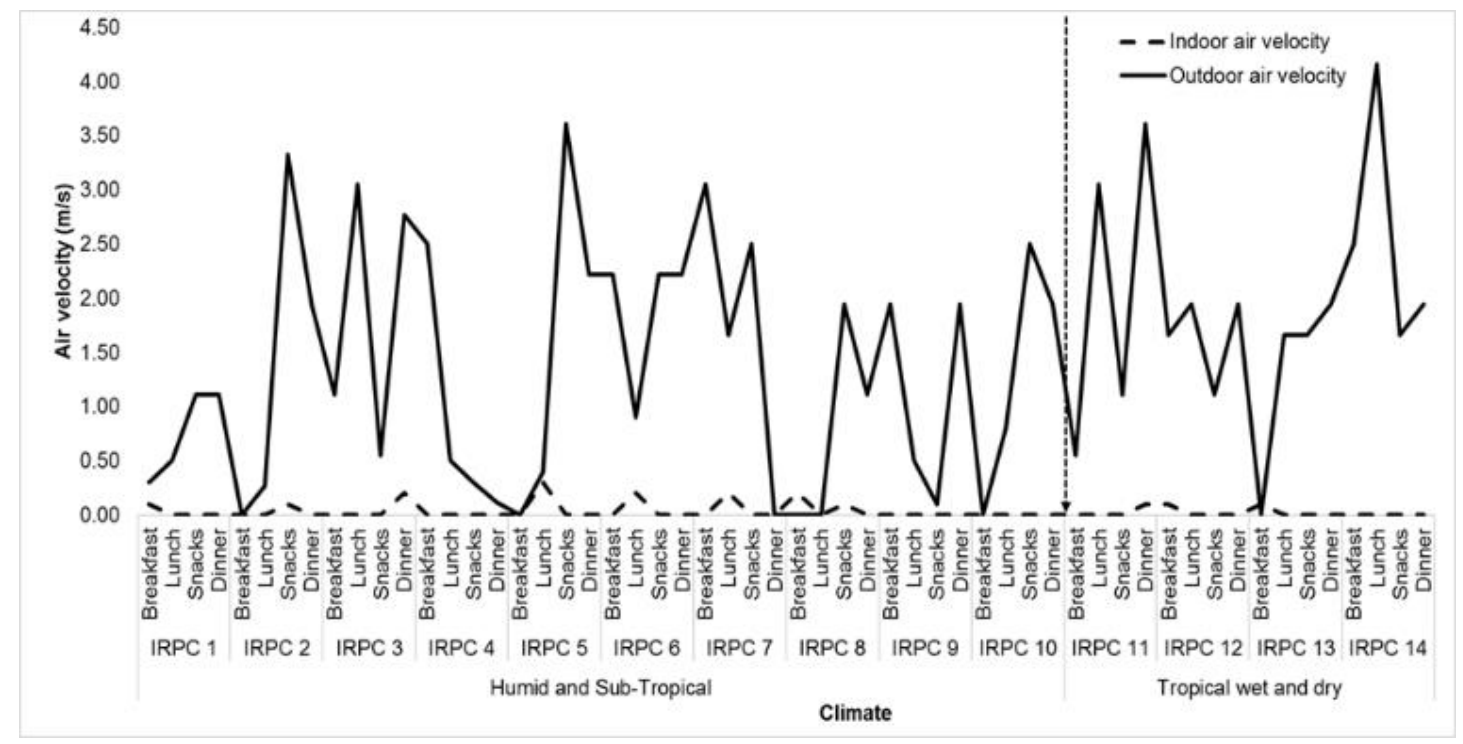

(b) Climate

Figure 5. Indoor and outdoor air velocity graph based on (a) season, and (b) climatic zone

\subsubsection{Air velocity}

Figure 5 (a) demonstrates that air velocity values both indoor and outdoor environmental conditions during the summer and winter season. In a summer season, indoor and outdoor air velocity was within $0.00 \mathrm{~m} / \mathrm{s}$ to $0.20 \mathrm{~m} / \mathrm{s}$ and 0.00 $\mathrm{m} / \mathrm{s}$ to $3.61 \mathrm{~m} / \mathrm{s}$ respectively. The average air velocity was 0.03 $\mathrm{m} / \mathrm{s}$ and $1.43 \mathrm{~m} / \mathrm{s}$ observed for indoor and outdoor conditions during the whole summer season. During the winter season, the air velocity in the indoor environment was found from 0.00 $\mathrm{m} / \mathrm{s}$ to $0.30 \mathrm{~m} / \mathrm{s}$ with an average $0.03 \mathrm{~m} / \mathrm{s}$, which was almost the same as the summer season. Whereas the outdoor air velocity was observed range $0.00 \mathrm{~m} / \mathrm{s}$ to $4.16 \mathrm{~m} / \mathrm{s}$ with an average $1.54 \mathrm{~m} / \mathrm{s}$. There is no difference in movement of indoor air velocity in both seasons. Inside the pantry car, no significant movement of air velocity was found at the time of cooking. However, during this time the outdoor wind speed measured was very high. According to the recommended value of "ASHRAE 55 Standard [20]", the air velocity should be for summer $(<0.25 \mathrm{~m} / \mathrm{s})$ and winter $(<0.15 \mathrm{~m} / \mathrm{s})$.

Figure 5 (b) shows the estimated effect of indoor and outdoor air movement in two different climate zone. In humid and sub-tropical climate zone, the minimum and maximum indoor air velocity were found $0.00 \mathrm{~m} / \mathrm{s}$ and $0.30 \mathrm{~m} / \mathrm{s}$ respectively with mean value $0.04 \mathrm{~m} / \mathrm{s}$. Whereas the outdoor air velocity was measured; minimum and maximum $0.0 \mathrm{~m} / \mathrm{s}$ and $361 \mathrm{~m} / \mathrm{s}$ respectively with an average value of $1.33 \mathrm{~m} / \mathrm{s}$. Entirely in this climate zone the indoor air velocity was found less. While in tropical wet and dry climate zone, the indoor and outdoor air velocity was observed during the cooking time $0.00 \mathrm{~m} / \mathrm{s}$ to $0.10 \mathrm{~m} / \mathrm{s}$ and $0.00 \mathrm{~m} / \mathrm{s}$ to $4.16 \mathrm{~m} / \mathrm{s}$ respectively and the average value of both was $0.02 \mathrm{~m} / \mathrm{s}$ and $1.91 \mathrm{~m} / \mathrm{s}$.

\subsection{Evaluation of PMV-PPD index}

In this study, a thermal comfort condition of chefs during the meal preparation period in the pantry cars were estimated based on a PMV-PPD index method. The PMV model predicted the mean impedance of a huge bunch of individuals exposed to a determinate environment following the "7-point thermal sensation scale" concurring to the ASHRAE Standard. And PPD is the "predicted percentage of dissatisfied" people at each level of PMV. A thermal comfort criterion necessitates the PPD value to be lower than " $10 \%$ to correspond to a PMV" value of between range -0.5 "slightly cool sensation" and +0.5 "slightly warm sensation". Thermal comfort result of pantry car kitchens during the cooking period/time (breakfast, lunch, snacks, and dinner) based on the seasons and climatic zones are depicted in Table 5.

During the summer season, the maximum PMV value of 2.97 was estimated with $97.33 \%$ PPD during the preparation of lunch. While minimum PMV value 2.43 was found at the time of breakfast preparation with PPD $87.83 \%$. Similarly, in the winter season, maximum value of PMV 1.91 was calculated with $70.25 \%$ of PPD at lunch cooking period. While minimum value of PMV 1.28 was found with $40.75 \%$ PPD at breakfast time. However, the value of PMV-PPD index was found more during other time cooking periods also in both seasons. In a humid and subtropical climate zone, maximum PMV value 2.33 and 2.32 was found at the time of snacks and lunch with PPD $81.20 \%$ and $79.30 \%$ respectively. Similarly, in a tropical wet and dry climate zone, the maximum value of PMV and PPD index was found at lunch cooking period 2.48 and $88.25 \%$ respectively. Entirely in both seasons and climate zones, the calculated mean value of PMV and PPD index does not comply with the ASHRAE 55 standard. Even if the mean PMV index values are within the PMV standard range -3 to +3 (view Table 5). But many individual values are outside this standard range (view Figure 6), demonstrating that the PMV method is not practically applicable in every context; "ISO Standard EN 7730 [25]" recommends using the PMV value only in the interval -2 to +2 , meaning that most of the measured conditions are outside the range, indicating a high percentage of dissatisfaction. PMV and PPD index method is not directly suitable for thermal comfort application of pantry car kitchen because of high temperature, high activity, and less air movement. 
Table 5. Average data of field measurements and thermal comfort indices during cooking period based on season and climatic zone

\begin{tabular}{cccccccccc}
\hline & & \multicolumn{4}{c}{ Input parameters } & \multicolumn{4}{c}{ Output } \\
\hline Season & Cooking period & $t_{a}\left({ }^{\circ} \mathrm{C}\right)$ & $t_{m r t}\left({ }^{\circ} \mathrm{C}\right)$ & $\mathrm{RH} \%$ & $v_{a}, \mathrm{~m} / \mathrm{s}$ & $\mathrm{Clo}$ & met & PMV & PPD \\
\hline Summer & Breakfast & 30.92 & 30.75 & 74.97 & 0.03 & 0.58 & 2.0 & 2.43 & 87.83 \\
& Lunch & 33.85 & 33.00 & 77.33 & 0.00 & 0.58 & 2.0 & 2.97 & 97.33 \\
& Snacks & 33.22 & 33.08 & 76.00 & 0.02 & 0.58 & 2.0 & 2.92 & 95.5 \\
& Dinner & 32.39 & 31.88 & 76.15 & 0.02 & 0.58 & 2.0 & 2.70 & 92.58 \\
Winter & Breakfast & 26.85 & 23.35 & 67.75 & 0.04 & 0.58 & 2.0 & 1.28 & 40.75 \\
& Lunch & 31.70 & 26.10 & 61.68 & 0.09 & 0.58 & 2.0 & 1.91 & 70.25 \\
& Snacks & 29.75 & 26.33 & 64.63 & 0.01 & 0.58 & 2.0 & 1.84 & 67.75 \\
& Dinner & 27.65 & 25.20 & 61.59 & 0.00 & 0.58 & 2.0 & 1.53 & 52.13 \\
\hline Climate & Cooking time & $t_{a}\left({ }^{\circ} \mathrm{C}\right)$ & $t_{m r t}\left({ }^{\circ} \mathrm{C}\right)$ & $\mathrm{RH} \%$ & $v_{a}, \mathrm{~m} / \mathrm{s}$ & $\mathrm{Clo}$ & met & PMV & PPD \\
\hline Humid and Subtropical & Breakfast & 28.85 & 26.82 & 69.78 & 0.03 & 0.55 & 2.0 & 1.80 & 62.30 \\
& Lunch & 32.69 & 28.62 & 69.70 & 0.07 & 0.55 & 2.0 & 2.32 & 79.30 \\
& Snacks & 31.46 & 29.31 & 69.40 & 0.02 & 0.55 & 2.0 & 2.33 & 81.20 \\
Tropical wet and dry & Dinner & 29.02 & 28.13 & 68.92 & 0.02 & 0.55 & 2.0 & 1.93 & 67.00 \\
& Breakfast & 27.95 & 25.78 & 73.50 & 0.05 & 0.64 & 2.0 & 1.69 & 57.50 \\
& Lunch & 32.45 & 30.15 & 65.10 & 0.00 & 0.64 & 2.0 & 2.48 & 88.25 \\
& Snacks & 30.68 & 29.00 & 69.75 & 0.00 & 0.64 & 2.0 & 2.25 & 75.75 \\
& Dinner & 29.85 & 29.50 & 62.93 & 0.03 & 0.64 & 2.0 & 2.20 & 73.00 \\
\hline
\end{tabular}

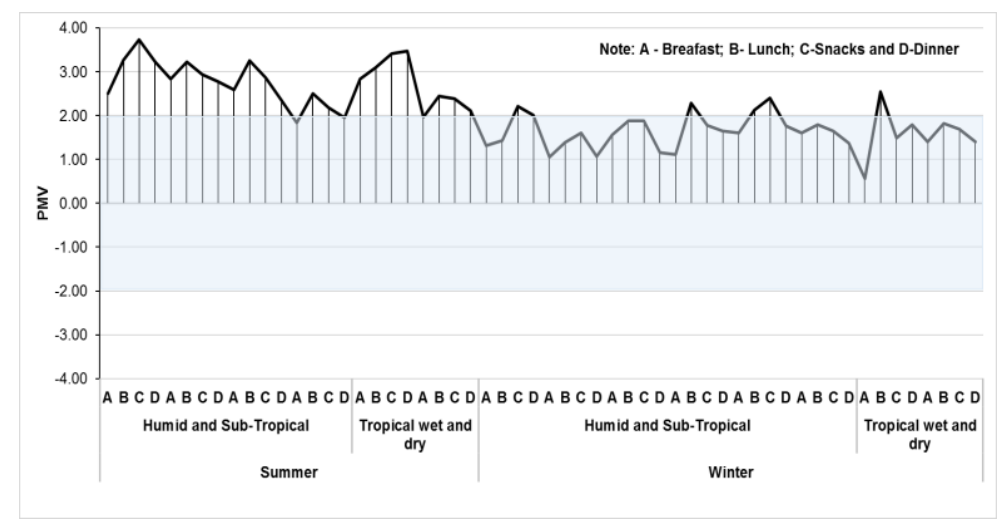

Figure 6. Distribution of PMV value at the cooking time

\subsection{Subjective assessment}

Demographic detail of the railway pantry car chefs is presented in Table 6 with data being presented, like mean (SD), range, and percentages. The chef's age ranges from 24 to 51 years ( mean $=36.87$ years; $\mathrm{SD}=6.36$ years). Maximum $36.23 \%$ of chefs were having work experience between $3-5$ years, while minimum $10.14 \%$ of pantry car chefs were having work experience less than one year. Another majority of the chefs had worked in the pantry car for more than five years.

Figure 7 demonstrates the subjective responses to thermal comfort votes (TCV) from -3 "much too cool", -2 "too cool", -1 "ok cool", 0 "ok just right", +1 "ok warm", +2 "too warm", +3 "much too warm". During the summer season, the results show that $65.5 \%$ of the 19 respondents from the humid and sub-tropical climate zone voted sensation value $(+1,+2$ and $+3)$. While for the tropical wet and dry climate region, the alue of votes was $(+1,+2,+3)$ which consists of $34.5 \%$ of the 10 respondents. All the thermal comfort votes in both climate zones were found on the "hot" side only during the summer season and its vote range was +1 to +3 .

Similarly, in the winter season, $75 \%$ of the 30 respondents from the humid and sub-tropical climate zone voted sensation value $(+1,+2,+3)$. Although similar in the tropical wet and dry climatic zones, $25 \%$ of the 10 respondents voted for sensational range value +1 to +3 . Inside the pantry car, none of the respondents have voted for cool sensation even during the winter season in both climate zones. Most of the respondents have voted on the hot range side, which is out of the acceptable range. As ASHRAE 55 Standard [20] specifies that $80 \%$ of people living in acceptable thermal environments should vote for the central three categories " $-1,0,+1 "$. In this study, no respondents' votes were found especially with central three categories.

Table 6. Demographic details of railway pantry car chefs (n $=69)$

\begin{tabular}{|c|c|}
\hline Age (years) & \\
\hline Mean (SD) & $36.87(6.36)$ \\
\hline Range & $24-51$ \\
\hline Weight (kg) & $68.18(6.28)$ \\
\hline Mean (SD) & $55-84$ \\
\hline Range & \\
\hline Height $(\mathrm{cm})$ & $171.03(5.17)$ \\
\hline Mean $(\mathrm{SD})$ & $160.02-182.88$ \\
\hline Range & 10.14 \\
\hline Job experience $(\%$ sample) & 21.76 \\
\hline$<1$ year & 36.23 \\
\hline 1-2 years & 31.87 \\
\hline 3-5 years &
\end{tabular}




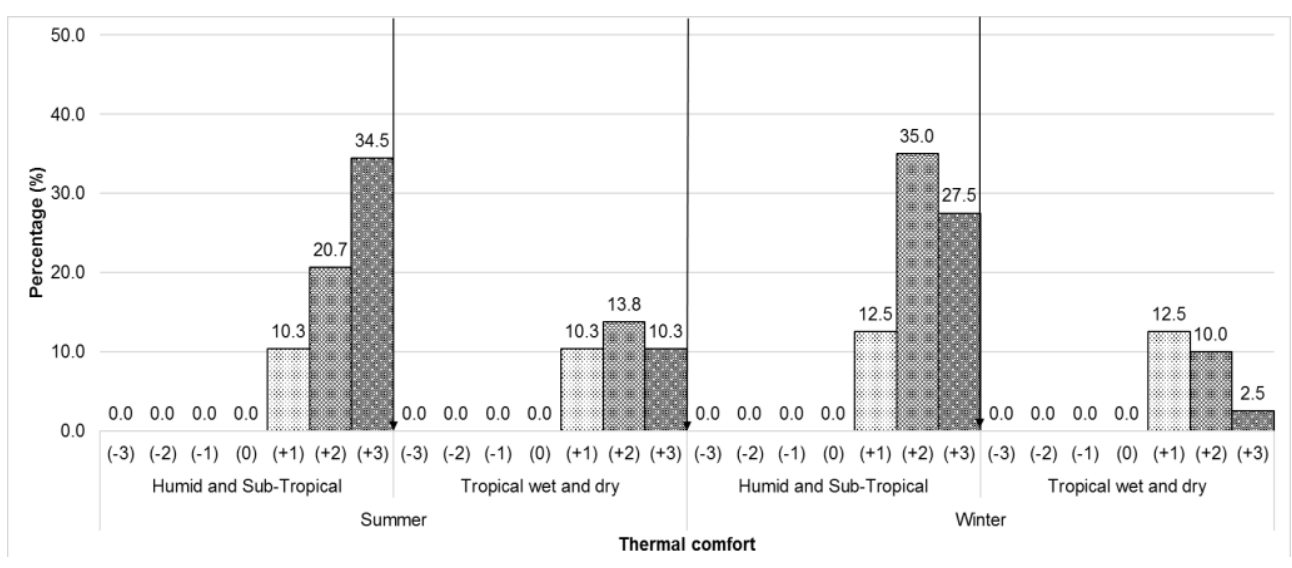

Figure 7. Dispensation percentage of subjective response to thermal comfort

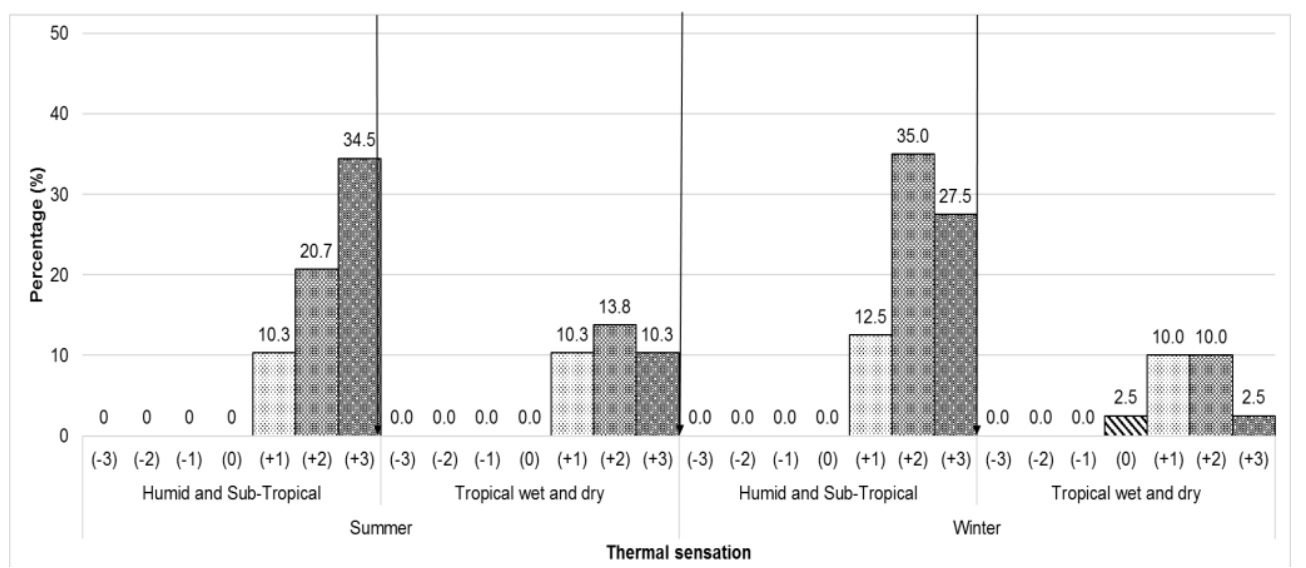

Figure 8. Dispensation percentage of subjective response to thermal sensation

Figure 8 demonstrate the subjective responses to thermal sensation votes (TSV) from 3 "cold", 2 "cool", 1 "slightly cool", 0 "neutral", +1 "slightly warm", +2 "warm", +3 "hot". At the time of summer season in a humid and subtropical climate zone, $66 \%$ responded voted from the range +1 to +3 . Even in the tropical wet and dry climate areas, $34 \%$ of respondent's votes ranged from +1 to +3 . In both climatic zones, there is no vote in the entire summer season according to the central three categories. During the winter season in the humid and subtropical climate zone, votes ranged +1 to +3 which consists of $75 \%$ of the 30 respondents. While for the tropical wet and dry climate region, the votes are from 0 to +3 , in which there are $25 \%$ of 10 respondents. In this climatic zone also does not follow the central three categories mentioned above $(-1,0,+1)$. Respondents have not given TSV in the negative (cool) side in this study. While only 1 respondent did vote in 0 (neutral), but the votes of all the other respondents who do not follow the standard.

Occupants' (chefs) perception of thermal acceptability based on the season and climate is an exhibit in Figure 9. The rating scale: Acceptable (0) and Not acceptable (1) was used to obtain the occupants' thermal acceptability response. It observed that during the summer season in both climate zones, $24 \%$ of respondents accepted the thermal environment and the other $76 \%$ did not accept it. Similarly, during the winter season in both climatic zones, only $5 \%$ of chefs accepted the thermal environment while $95 \%$ did not accept it. As many studies have suggested, the percentage of respondent satisfaction in any thermal environment should be above $80 \%[26,27]$. Where's the percentage of the chef's satisfaction in the pantry car kitchen environment is very low.

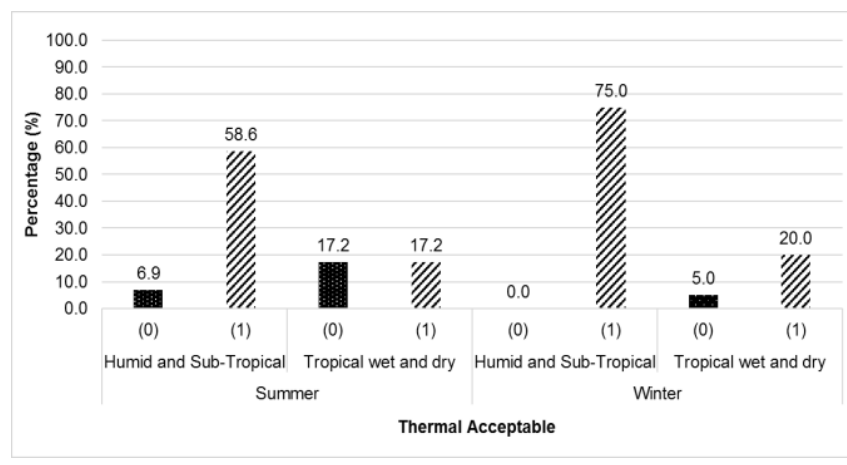

Figure 9. Dispensation percentage of subjective response to thermal acceptability

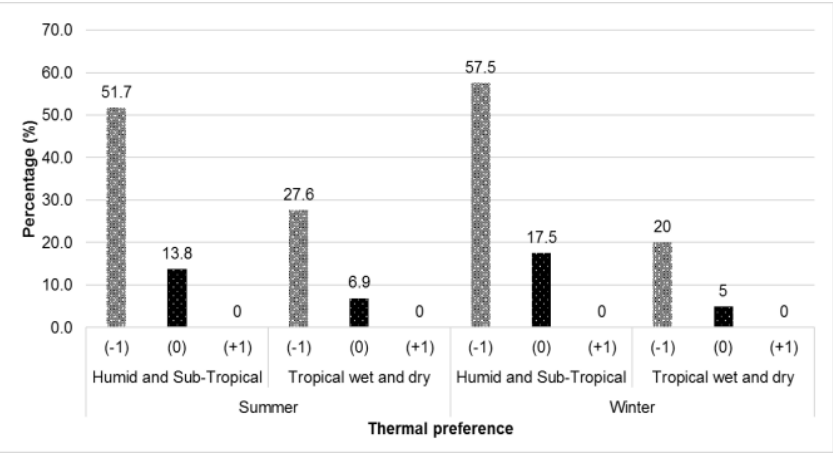

Figure 10. Dispensation percentage of subjective response to thermal preference 
Figure 10 demonstrates the dispensation percentage of subjective response to thermal preference based on the seasonal variation and climate zone. Thermal preference was estimated directly according to the answer to the question: In the pantry car kitchen environment would you like to be, -1 "cooler", 0 "no change", +1 "warmer". It can be seen that throughout the summer season in both climate zones, $79.3 \%$ of the chefs want to prefer in the "cooler" side. While $20.7 \%$ of the chefs preferred with the existing environment inside the pantry car. None of the chefs preferred the "warmer" side. Similarly, at the time of winter season in both climatic zones, $77.5 \%$ of the chefs want to prefer in "cooler" side, and $22.5 \%$ of the chefs preferred with the existing environment. Throughout the winter season in both climate zones, no anyone preferred to "warmer" side. However, in both season and climatic zones, some respondents preferred staying with the environment inside the pantry car due to cooking habits. As such, some thermal comfort studies have also been reported that the largest part of the subjects does not want any change in their workplace zone [28]. But in this result, most of the respondents prefer to stay on the cool side.

\subsection{Neutral temperature and comfort temperature range}

In this research to predict the Tn "neutral temperature" and Tcr "comfort temperature range", regression analyses were carried out using "M S Excel 2016". Figure 11 (a) and (b), demonstrate the regression line of "thermal sensation votesTSV" on "air temperature-Ta" in summer and winter are:

Summer:

$$
\mathrm{TSV}=0.2193 \mathrm{Ta}-4.8324 \quad \mathrm{r}^{2}=0.5315
$$

Winter:

$$
\mathrm{TSV}=0.2646 \mathrm{Ta}-5.6207 \quad \mathrm{r}^{2}=0.3024
$$

The coefficient of the determinant $\left(\mathrm{r}^{2}\right)$ between TSV and the Ta in summer is 0.5315 for Eq. (2) and in winter is 0.3024 for Eq. (3).

Table 7 demonstrates the neutral "comfort" temperature and comfort range of chefs in the railway pantry car. The neutrality condition during summer and winter season is derived by solving Eqns. (2-3) for a thermal sensation vote of zero. While the comfort temperature was determined on the basis of ASHRAE 55 standard, in which the "comfort zone" is defined as a limitation of thermal environmental conditions more than $80 \%$ of living people express satisfaction. So, the percentages of dissatisfaction resulting from votes above "central three categories $(-1,0,+1)$ " of ASHRAE scales in each temperature bin were plotted as a function of air temperature.

During the summer season in the pantry car, chef's neutral temperature was $23^{\circ} \mathrm{C}$ Ta, while the comfort temperature range was $18.50-27.80^{\circ} \mathrm{C}$ Ta. Similarly, during the winter season in the pantry car, chef's neutral temperature was $21.62^{\circ} \mathrm{C} \mathrm{Ta}$, whereas the comfort temperature range was $17.80-25.50^{\circ} \mathrm{C} \mathrm{Ta}$.

When comparing to ASHRAE's comfort range during the summer season, $24.5-27.0^{\circ} \mathrm{C}$, the comfortable range for chefs shifts to "slightly warm temperatures" by about $0.80^{\circ} \mathrm{C}$. Similarly, comparing to ASHRAE's comfort range during the winter season, $19.5-22.5^{\circ} \mathrm{C}$, the comfortable range for chefs shifts to warm temperatures by about $3^{\circ} \mathrm{C}$. This finding indicates a completely different phenomenon. Because pantry car chefs have differently acclimated to the climate. Similar types of research also have been done by the authors in other studies which indicated below.

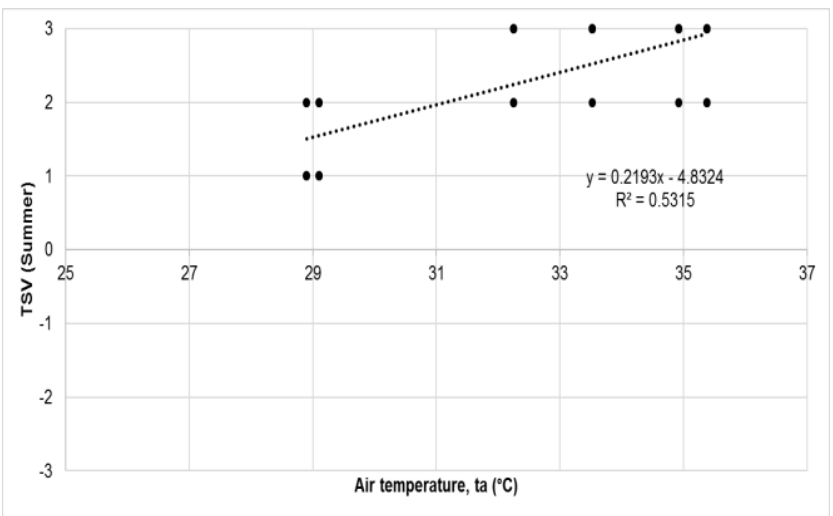

(a) Summer

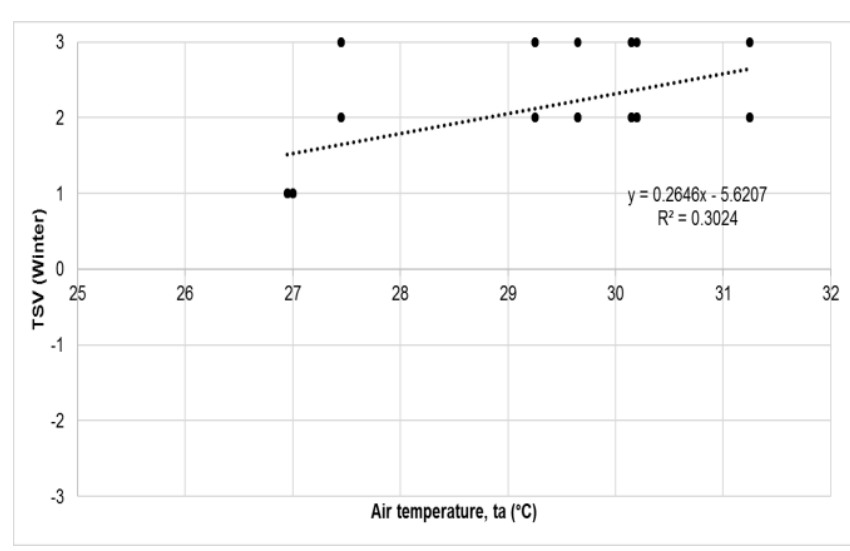

(b)Winter

Figure 11. The regression analyses between the TSV and $T_{a}$ during (a) summer and (b) winter, season inside the pantry car

Table 7. Summer and winter season $T n$ and $T c r$ for chefs inside the pantry car

\begin{tabular}{cccccc}
\hline Season & $\mathbf{T n}\left({ }^{\circ} \mathbf{C}\right)$ & Tcr $\left({ }^{\circ} \mathbf{C}\right)$ & Regression Equation & $\mathbf{r}^{2}$ & Significance \\
\hline Summer & 23 & $18.50-27.80$ & $\mathrm{TSV}=0.2193 \mathrm{Ta}-4.8324$ & 0.5315 & $\mathrm{p}<0.01$ \\
Winter & 21.62 & $17.80-25.50$ & $\mathrm{TSV}=0.2646 \mathrm{Ta}-5.6207$ & 0.3024 & $\mathrm{p}<0.01$ \\
\hline
\end{tabular}

3.4.1 Subjects neutral temperature compare with other Studies

Various researchers have studied to identify neutral temperatures in their thermal comfort work, which is shown in Table 8. Chan et al. [29] organized thermal comfort research on office premises in Hong Kong to improve the work environment.
Similarly, in China Ye et al. [30] finished the research on the passenger train's coaches to determine the thermal environment and thermal comfort. Accordingly, Lin et al. [31] directed the thermal comfort study in "short-and long-haul" buses and trains among the passengers in Taiwan. Hwang and Cheng [32] reported on "human thermal comfort in air- 
conditioned offices workers in Taiwan", in which compared the computed comfort temperature to ASHRAE standard 55. Similar research conducted by Hamzah et al. [33] in "Indonesia" on naturally ventilated university classrooms to understand the "thermal environment condition and subjects responses", In which also compared the computed comfort temperature to ASHRAE standard 55 and Indonesian National Standard. Karyono [34] also finished a similar kind of research in Indonesia on university students to identify the comfort temperature among them. Hussein et al. [35] conducted the study in Malaysia on "air-conditioned and non-air-conditioned two schools buildings". In which compared the calculated neutral (comfort) temperature with the ASHRAE comfort standard. Deb and Ramachandraiah [1] conducted research on passenger thermal comfort in south railway stations in India to investigate the neutral temperature.

Table 8. A summary of subjects neutral temperature some previous thermal comfort studies

\begin{tabular}{ccc}
\hline Researcher & Country/Location & Neutral temperature \\
\hline Chan DW et al. & Hong Kong & $23.5^{\circ} \mathrm{C}$ \\
Ye XJ et al. & China & $23.3^{\circ} \mathrm{C}$ \\
Lin TP et al. & Taiwan & $26.2^{\circ} \mathrm{C}$ and $27.4^{\circ} \mathrm{C}$ \\
Hwang RL, Cheng MJ & Taichung, Taiwan & $25.6^{\circ} \mathrm{C}$ \\
Hamzah B et al. & Makassar, Indonesia & $24.1^{\circ} \mathrm{C}$ \\
Karyono TH & Jakarta, Indonesia & $24.1^{\circ} \mathrm{C}$ \\
Hussein I et al. & Malaysia & $24.4^{\circ} \mathrm{C}$ and $28.4^{\circ} \mathrm{C}$ \\
Deb C, Ramachandraiah A & Chennai, India & $31.93^{\circ} \mathrm{C}$ \\
\hline
\end{tabular}

\section{CONCLUSIONS}

The objective assessment indicates that the outdoor thermal comfort parameters have an effect on the indoor thermal comfort parameters during the seasonal and climatic variation at the time of cooking inside the pantry car. The maximum range of thermal comfort parameters was found at the preparing of lunch and snack time and minimum range at the time of breakfast. The indoor physical condition of "air temperature, globe temperature, relative humidity, and air velocity" were out of the limits of thermal comfort standards. During each cooking period (breakfast, lunch, snacks, and dinner) inside the pantry car, the calculated value of the PMVPPD index method does not comply with the ASHRAE 55 and ISO 7730 standard. A PMV-PPD index is not suitable for the thermal comfort application of pantry car kitchen due to high temperature. The subjective assessment towards "thermal sensation, thermal comfort, thermal acceptability, and thermal preference votes" generally indicates that the chefs were dissatisfied with the existing condition in the pantry car kitchens.

The thermal neutrality of chefs occurred at $23^{\circ} \mathrm{C}$ and $21.62^{\circ} \mathrm{C}$ during the summer and winter season respectively. Similarly, responses from those chefs suggest a comfort temperature range during summer and winter season was found $18.50-27.80{ }^{\circ} \mathrm{C}$ and $17.80-25.50{ }^{\circ} \mathrm{C}$, respectively, that shifts to slightly warm temperature for summer and warmer temperature for winter by about $0.80{ }^{\circ} \mathrm{C}$ and $3{ }^{\circ} \mathrm{C}$ as comparing to comfort zone recommended in ASHRAE 55 standard. When compared to neutral temperatures found in other countries with hot-humid climate, observation shows that living in the pantry car appears less tolerant.

The workplace design of the chef (includes ventilation/windows/air-supply/layouts-design) for future development could be improved through the application of thermal comfort range and neutral temperature values. Furthermore, the proposed regression models could be used instead of the PMV/PPD index method for the thermal comfort assessment of chefs in railway pantry cars kitchens.

\section{REFERENCES}

[1] Deb, C., Ramachandraiah, A. (2010). Evaluation of thermal comfort in a rail terminal location in India. Building and Environment, 45(11): 2571-2580. https://doi.org/10.1016/j.buildenv.2010.05.023

[2] Neeraj, K. (2012). Rolling Stock Indian Railways YearBook 2010-11. Ministry of Railways Government of India, 5-67.

[3] Patil, P., Mukul, S., Mathur, S. (2012). How to improve catering services in Indian Railways. International Union of Railways, 7-52.

[4] Vidhale, A.A., Palekar, A.D., Kanchan, A.G. (2014). Automated pantry car system. International Journal of Advanced Research in Computer Science and Software Engineering, 4(2): 692-699.

[5] Pethkar, G., Jadhav, S., Dhumal, P., Bhosale, P., Ahir, P.R. (2015). Automated pantry car system in India using RF module and GSM technology. International Journal of Advanced Research in Electronics and Communication Engineering, 4(4): 794-797.

[6] Alam, M.S., Arunachalam, M., Salve, U.R. (2019). A pilot study on thermal comfort in Indian Railway pantry car chefs. Journal of Physics: Conference Series, 1240(1): 012033. 6596/1240/1/012033

[7] Matsuzuki, H., Ito, A., Ayabe, M., Haruyama, Y., Tomita, S., Katamoto, S., Muto, T. (2011). The effects of work environments on thermal strain on workers in commercial kitchens. Industrial Health, 49(5): 605-613. https://doi.org/10.2486/indhealth.MS1219

[8] Ravindra, K., Agarwal, N., Kaur-Sidhu, M., Mor, S. (2019). Appraisal of thermal comfort in rural household kitchens of Punjab, India and adaptation strategies for better health. Environment International, 124: 431-440. https://doi.org/10.1016/j.envint.2018.12.059

[9] Rahmillah, F.I., Tumanggor, A.H.U., Sari, A.D. (2017). The analysis of thermal comfort in kitchen. IOP Conference Series: Materials Science and Engineering, 215(1): $\quad 012033 . \quad$ https://doi.org/10.1088/1757899X/215/1/012033

[10] Kajtar, L., Banhidi, L., Leitner, A. (2005). Air quality and thermal comfort in kitchens. Proceedings: Indoor Air, pp. 2371-2375.

[11] Wei, P., Zhou, B., Tan, M., Li, F., Lu, J., Dong, Z., Xu, M., Wang, G., Xiao, Y. (2017). Study on thermal comfort 
under non-uniform thermal environment condition in domestic kitchen. Procedia Engineering, 205: 2041-2048. https://doi.org/10.1016/j.proeng.2017.10.084

[12] Livchak, A., Schrock, D., Sun, Z. (2005). The effect of supply air systems on kitchen thermal environment. ASHRAE Transactions, 111(1): 748-754.

[13] Simone, A., Olesen, B.W., Stoops, J.L., Watkins, A.W. (2013). Thermal comfort in commercial kitchens (RP1469): Procedure and physical measurements (Part 1). HVAC and R Research, 19(8): 1001-1015. https://doi.org/10.1080/10789669.2013.840494

[14] American Society of Heating, Refrigerating and AirConditioning Engineers. (2010). Thermal environmental conditions for human occupancy. Atlanta: ASHRAE Standard-55.

[15] Simone, A., Olesen, B.W. (2013). Thermal environment evaluation in commercial kitchens of United States. In Clima 2013: 11th REHVA World Congress and 8th International Conference on IAQVEC.

[16] Mishra, A.K., Ramgopal, M. (2014). Thermal comfort in undergraduate laboratories-A field study in Kharagpur, India. Building and environment, 71: 223-232. https://doi.org/10.1016/j.buildenv.2013.10.006

[17] International Organisation for Standardisation. (2005). Moderate thermal environments-determination of the PMV and PPD indices and specification of the conditions for thermal comfort. Geneva, Switzerland, ISO Standard7730 .

[18] Ainsworth, B.E., Haskell, W.L., Whitt, M.C., Irwin, M.L., Swartz, A.M., Strath, S.J., O Brien, W.L., Bassett, D.R., Schmitz, K.H., Emplaincourt, P.O., Jacobs, D.R. (2000). Compendium of physical activities: An update of activity codes and MET intensities. Medicine and Science in Sports and Exercise, 32(9-1): 498-504. https://doi.org/10.1097/00005768-200009001-00009

[19] American Society of Heating, Refrigerating and AirConditioning Engineers. (2017). Thermal environmental conditions for human occupancy, Atlanta: ASHRAE Standard-55.

[20] American Society of Heating, Refrigerating and AirConditioning Engineers. (2004). Thermal environmental conditions for human occupancy, Atlanta: ASHRAE Standard-55.

[21] International Organisation for Standardisation. (2006). Ergonomics of the thermal environment-Evaluation of thermal environments in vehicles-Part 3: Evaluation of thermal comfort using human subjects, Geneva, Switzerland, ISO Standard-14505-3.

[22] International Organisation for Standardisation (1995). Ergonomics of the thermal environment-assessment of the influence of the thermal environment using subjective judgemental scale, ISO Standard 10551.

[23] American Society of Heating, Refrigerating and AirConditioning Engineers. (2016). Ventilation for acceptable indoor air quality, ASHRAE Standard-55.
[24] Valsson, S., Bharat, A. (2011). Impact of air temperature on relative humidity-a study. Architecture-Time Space and People, 38-41.

[25] International Organisation for Standardisation. (2005). Ergonomics of the thermal environment-analytical determination and interpretation of thermal comfort using calculation of the PMV and PPD indices and local thermal comfort criteria, ISO Standard-EN 7730.

[26] Nasrollahi, N., Knight, I., Jones, P. (2008). Workplace satisfaction and thermal comfort in air conditioned office buildings: Findings from a summer survey and field experiments in Iran. Indoor and Built Environment, 17(1): 69-79. https://doi.org/10.1177/1420326X07086945

[27] Streinu-Cercel, A., Costoiu, S., Marza, M. (2008). Models for the indices of thermal comfort. Journal of Medicine and Life, 1(2): 148-156.

[28] Hwang, R.L., Cheng, M.J., Lin, T.P., Ho, M.C. (2009). Thermal perceptions, general adaptation methods and occupant's idea about the trade-off between thermal comfort and energy saving in hot-humid regions. Building and Environment, 44(6): 1128-1134. https://doi.org/10.1016/j.buildenv.2008.08.001

[29] Chan, D.W., Burnett, J., de Dear, R.J., Ng, S.C. (1998). A large-scale survey of thermal comfort in office premises in Hong Kong. Ashrae Transactions, 104: 1172.

[30] Ye, X.J., Lian, Z.W., Li, C.Z., Liu, Y.M., Liu, Q.Z. (2005). Field study of thermal environment in trains. In Proceedings of the 10th International Conference on Indoor Air Quality and Climate-Indoor Air'05, pp. 165169.

[31] Lin, T.P., Hwang, R.L., Huang, K.T., Sun, C.Y., Huang, Y.C. (2010). Passenger thermal perceptions, thermal comfort requirements, and adaptations in short-and longhaul vehicles. International Journal of Biometeorology, 54(3): 221-230. https://dx.doi.org/10.1007/s00484-0090273-9

[32] Hwang, R.L., Cheng, M.J. (2007). Field survey on human thermal comfort reports in air-conditioned offices in Taiwan. The Open Construction and Building Technology Journal, 1(1): 8-13. https://doi.org/10.2174/1874836800701010008

[33] Hamzah, B., Ishak, M.T., Beddu, S., Osman, M.Y. (2016). Thermal comfort analyses of naturally ventilated university classrooms. Structural Survey, 34(4-5): $427-$ 445. https://doi.org/10.1108/SS-12-2015-0055

[34] Karyono, T.H. (2000). Report on thermal comfort and building energy studies in Jakarta-Indonesia. Building and Environment, 35(1): 77-90. https://doi.org/10.1016/S0360-1323(98)00066-3

[35] Hussein, I., Rahman, M.H.A., Maria, T. (2009). Field studies on thermal comfort of air-conditioned and non air-conditioned buildings in Malaysia. 3rd International Conference on Energy and Environment (ICEE), Malacca, Malaysia, pp. 360-368. https://doi.org/10.1109/ICEENVIRON.2009.5398622 